\title{
A Contabilidade Decisorial e o Cálculo do Preço de Venda
}

1. Introdução. 2. Definições. 3. Conceituação do Problema. 4. Determinação do Preço-Base. 5. Conclusão.
Em artigos anteriores, publicados nesta mesma revista, 1 tivemos a oportunidade de expor, de um modo geral, os conceitos básicos empregados pela Contabilidade Decisorial (CD), que é um dos sistemas mais avançados de contrôle econômico e financeiro de emprêsas, e que vem sendo adotado, com indiscutível êxito, por várias emprêsas nacionais, após suas qualidades terem sido já comprovadas no exterior.

Comentamos as características do sistema no que diz respeito:

a) à apuração e apreciação do resultado econômico e posição patrimonial da emprêsa;

b) às análises de rentabilidade de produtos, linhas e filiais;

c) a uma melhor definição de responsabilidade pelos gastos da emprêsa;

d) e ao estabelecimento e acompanhamento do plano geral de atividade (plano de lucro, previsão financeira, plano de investimentos).

Pretendemos, agora, mostrar alguns dos recursos que a CD oferece para a determinação do preço de venda, e como essa determinação torna-se mais segura, objetiva e, ao mesmo tempo, flexível quando apoiada nos conceitos empregados pelo sistema.

A fim de auxiliar o leitor que não teve a oportunidade de ler os artigos precedentes, resumimos abaixo a definição dos principais conceitos empregados pelo sistema, que serão citados no desenvolvimento do trabalho.

\section{DEFINIÇŐES}

\subsection{Despesas proporcionais}

São despesas que acompanham o volume da produção e/ou

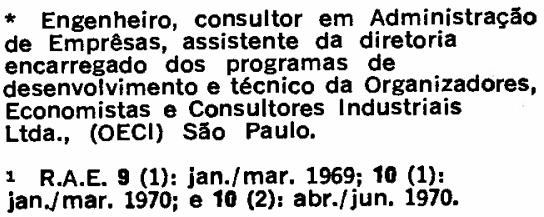

* Engenheiro, consultor em Administração de Emprêsas, assistente da diretoria encarregado dos programas de desenvolvimento e técnico da Organizadores, Economistas Consultores Industriais Ltda., (OECl) São Paulo.

1 R.A.E. 9 (1): jan./mar. 1969; 10 (1): jan.Jmar. 1970; e 10 (2): abr./ jun. 1970 
vendas. Podemos ter despesas proporcionais de fabricação (ou produção) e despesas proporcionais de comercialização (ou venda).

\subsection{Despesas fixas}

São aquelas que não dependem, a curto prazo, do volume de produção e de vendas.

São consideradas em dois grupos:

a) Despesas regulares: săo aquelas que além de fixas são pràticamente irrecorríveis; estão intimamente ligadas com a estrutura da emprêsa; qualquer modificação implica num processo de mecanização e/ou racionalização de serviços, ou acarreta uma solução de continuidade nos processos administrativos ou produtivos da emprêsa.

b) Despesas programadas: são aquelas que podem sofrer variações mais drásticas, a curto prazo, sem acarretar solução de continuidade nos serviços; elas são de decisão da alta administração, como por exemplo: gastos com propaganda, com pesquisa de mercado ou de novos produtos, gratificações extras a funcionários e outras.

\subsection{Custo incremental ou custo direto}

E o custo de um produto calculado somente com as despesas proporcionais.

O Custo incremental de fabricação (CIF) é calculado sòmente com as despesas proporcionais de fabricação e pode ser decomposto em duas partes:

a) custo da matéria-prima $\mathrm{e}$

b) custo incremental de transformação (CITf) que engloba os demais gastos proporcionais de fabricação (mão-de-obra produtiva, energia, combustíveis, e outros), necessários para efetuar a modificação da matéria-prima em produto acabado. 0 esfôrço produtivo da emprêsa, de um certo modo, pode ser representado pelo montante das despesas de transformação.

\subsection{Custo incremental padrão}

Consiste na aplicação dos conceitos de custo-padrão ao custo incremental. Em geral, a parcela correspondente à fabricação é definida em valor e a referente às vendas através de uma porcentagem em relação ao faturamento ou preço de venda.

O estabelecimento do custo incremental padrão de fabricação (CIFPdr) é feito através de padrōes de quantidade (de matéria-prima, mão-de-obra e outras despesas) valorizados pelos respectivos padrões de preço. Enquanto os padrões de quantidade estão relacionados com 0 produto em si e com os métodos de fabricação empregados, os padrões de preço estão ligados mais às contingências externas (preço das matérias-primas, salário dos empregados produtivos, custo de energia e assim por diante).

O custo incremental padrão de transformação (ver item 2.3) pode ser empregado para medir, de um modo aproximado, quanto da capacidade produtiva da emprêsa o produto absorve.

Essa capacidade, designada capacidade produtiva útil pode ser conhecida pelo montante de gastos de transformação que a emprêsa teria quando em operação a plena carga. 0 seu cálculo é feito somando-se o produto das unidades de trabalho (UT) úteis pelas respectivas taxas-padrão, dos diversos centros produtivos.

\subsection{Contribuição marginal $(\mathrm{Cm})$}

$E$ a diferença entre o valor de uma venda e os gastos proporcionais a ela referentes.
Pode ser relacionada a um produto em particular, a um grupo de produtos, a uma filial e à emprêsa de um modo global.

Em uso corrente, a contribuição marginal é apreciada em valor absoluto, em porcentagem em relação ao valor da venda ou em forma de índice em relação ao custo-padrão de transformação (medindo a capacidade produtiva absorvida) correspondente. Em alguns casos, usam-se também as relaçōes da contribuição marginal com outras medidas de produção, como por exemplo: contribuição marginal por tonelada, por hora $x$ máquina, por hora $x$ homem, e outras, e até mesmo com o capital necessário à sua realização (quando fôr possivel determiná-lo).

\section{CONCEITUAÇAOO DO PROBLEMA}

O problema da determinação de preços, geralmente, está mais ligado a uma imposição de mercado do que ao seu custo (salvo, evidentemente, algumas exceções). Segundo Joel Dean, 2 os custos seriam usados para:

a) medir os efeitos das alternativas de preço sôbre o lucro;

b) adivinhar a reação dos competidores em resposta a um preço lançado;

c) justificar preços (ou alterações) perante órgãos governamentais, cliente ou público.

Dentro dêsse panorama, a utilização do custo por absorção, embora freqüentemente usado, apresenta-se assaz deficiente. Esse tipo de custo incorpora ao produto despesas que são fixas (independentes do volume de produção e/ou vendas) $e$, portanto, o custo assim calculado sofrerá influência das oscilações do volume de

- Dean, Joel. Economia de empressas. Rlo de Janeiro, Editóra Fundo de Cultura. 
negócios, decorrentes mesmo da própria comercialização do produto em questão (casos de concorrências públicas, por exemplo). Dessa forma, torna-se difícil avaliar, no lucro da emprêsa, a influência de alternativas de preços que condicionem volumes diferentes de venda. Por outro lado, pode-se até deixar de vender produtos que aparentemente dão prejuízo, mas que, uma vez não vendidos, fazem com que se transfira para outros produtos aquela parcela de gastos fixos que êle deveria absorver, se fôsse vendido a preço de custo.

Os métodos mais seguros para cálculo de preço devem levar a um valor tal que:

a) traga à emprêsa o maior lucro possível (maior contribuição), levando em conta a contribuição marginal unitária e o volume de vendas a ser atingido, em decorrência do preço dado;

b) seja possível à emprêsa atender à demanda (venda) esperada àquele preço;

c) consiga-se o aproveitamento mais lucrativo dos meios de produção disponíveis:

capacidade de trabalho (esfôrço de transformação), equipamento, matérias-primas e capital de giro, entre outros.

Para tanto, deve ser levada em conta a situação econômico-financeira geral da emprêsa, de modo que os preços estabelecidos não venham agravar os pontos críticos, e possam aproveitar as situações favoráveis de outros aspectos para saná-los. Por exemplo, no caso de dificuldade de capital de giro pode-se baixar os preços (aproveitando folga de lucratividade) para reduzir os prazos de financiamento aos clientes ou aumentar a rotação dos estoques elevados. Também deverão ser levados em conta os aspectos promocionais do produto, cujo preço é então estudado em conjunto com o.dos produtos que promove.

Para se fixar um preço de venda, pode-se seguir, de um modo geral, o seguinte caminho:

a) determina-se um preço-base, utilizando-se dados internos da emprêsa;

b) faz-se uma crítica dêsse preço-base à luz das características conhecidas do mercado (preço dos concorrentes, pesquisa de mercado, volume provável de vendas);

c) ajusta-se o preço às condições do mercado e verificam-se os reflexos dêsse nôvo preço sôbre o lucro e demais aspectos econômico financeiros da emprêsa;

d) estudam-se outras alternativas pesquisando a relação volume $x$ preço, de modo a se conseguir uma melhoria do aspecto crítico;

\section{e) estabelece-se o preço mais} conveniente.

A seguir, mostraremos como os conceitos utilizados pela $C D$ podem ser empregados para o estabelecimento do preço-base e para o estudo das

alternativas impostas pelas condições do mercado.

\section{DETERMINAÇAO DO PREÇO-BASE}

Para a determinação do preço-base, a CD fundamenta-se na contribuição marginal $(\mathrm{Cm})$ que o produto deverá trazer para a emprêsa. Essa $\mathrm{Cm}$ unitária deve satisfazer as imposições da emprêsa de modo a não agravar (ou corrigir) seu aspecto crítico. Através de alguns exemplos, vamos mostrar o método de cálculo do preço-base, tendo em vista algumas situações especiais da emprêsa. Em todos os casos, é preciso ter sempre em mente que o preço-base calculado deve ser apreciado sob o ponto de vista do mercado e só então ser aceito ou rejeitado.

\subsection{Primeiro caso}

Vamos supor o caso da determinação do preço de um produto nôvo A, que irá substituir um antigo que se torna obsoleto, prevendo-se que - faturamento global da linha não vai ser sensivelmente alterado com essa substituição. Que condições devemos impor à $\mathrm{Cm}$ do nôvo produto de modo que a linha se mantenha nos mesmos níveis de rentabilidade?

Sendo êsse o caso, faremos o cálculo do preço-base de tal forma que a $\mathrm{Cm}$ do nôvo produto, em porcentagem em relação ao preço de venda, seja a mesma da linha ou do produto que está sendo substituído.

Teremos, então, os seguintes dados de partida:

Dados da linha: ${ }^{3}$

\begin{tabular}{lc}
\hline $\begin{array}{c}\text { Porcentagem de Contribuição } \\
\text { marginal }\end{array}$ \\
$\begin{array}{c}\text { Despesas proporcionais } \\
\text { de venda }\end{array}$ \\
\hline
\end{tabular}

\section{Dados do produto}

Custo incremental de fabricação (CIF): $\operatorname{Cr} \$ 53,00$

Colocando-se em duas colunas os valôres em cruzeiros e os valôres em porcentagem, teremos a seguinte situação:

\begin{tabular}{|c|c|c|c|c|}
\hline & & $\mathrm{Cr} \$$ & $\%$ & \\
\hline $\begin{array}{l}\text { Preço de } \\
\text { venda de } \\
\text { D.P.V. } \\
\text { CiF }\end{array}$ & A & $\frac{x}{53}$ & $\begin{array}{r}100,0 \\
20,0 \\
49,5\end{array}$ & ( $\%$ calculada por \\
\hline $\mathrm{Cm}$ & & - & 30,5 & \\
\hline
\end{tabular}

A porcentagem do CIF em relação ao valor da venda (preço) é obtida por diferença e será de 49,5\%. Como sabemos, o CIF decorre, imediatamente, do preço-base:

Preço-base de $A=X=\frac{53,00}{0,495}=107,00$

- Estamos aproveitando dados dos exemplos já apresentados nos artigos anteriores. 
A adoção dêsse preço fará com que o faturamento da linha continue trazendo uma contribuição marginal de $30,5 \%$ para a emprêsa.

Verifica-se, então, se êsse preço é aceitável no mercado, comparando-o com os de produtos similares de concorrentes, com o do artigo da companhia que está sendo substituído, com o resultado de pesquisas de mercado, etc.

Suponhamos que o mercado não agüente êsse preço, ou que, com um preço pouco mais baixo, poder-se-á ampliar a faixa de mercado e ter-se um aumento de volume compensador.

Então, sendo Cr\$95,00, por exemplo, o preço aceitável, a contribuição marginal $(\mathrm{Cm})$ a ser alcançada, em cruzeiros e em porcentagem, será:

$$
\mathrm{Cm}=\mathrm{Cr} 23,00 \quad \% \mathrm{Cm}=24,2 \%
$$

Mesmo com uma contribuição unitária inferior à dos demais produtos da linha, mas positiva, o produto absorverá uma quantia maior de despesas fixas, pelo aumento do volume. Restaria verificar se êsse aumento de vendas não irá estrangular a produção.

\subsection{Segundo caso}

Suponhamos o mesmo produto $A$, numa situação diferente: êle será introduzido na linha, não para substituir um outro, e absorverá, portanto, uma capacidade produtiva adicional. Estando a emprêsa trabalhando já a plena carga, a introdução de A será feita em detrimento de outros produtos que sofrerão redução no volume de produção e, conseqüentemente, do faturamento respectivo.

Devemos, portanto, para o cálculo do preço-base, impor que a $\mathrm{Cm}$ do nôvo produto traga um mesmo aproveitamento (em têrmos de lucro) da capacidade produtiva, ${ }^{4}$ ou seja, quer produzindo o nôvo produto, quer produzindo os antigos, 0 esfôrço de produção deve trazer, no mínimo, a mesma contribuição marginal para a emprêsa.

Supondo que a Capacidade Produtiva esteja sendo medida em têrmos de gastos de transformação, vamos impor que o nôvo produto tenha a relação $\mathrm{Cm} / \mathrm{ClTf}^{5}$ no mínimo igual aos demais.

Teremos, então, os seguintes dados do problema:

Dados da linha - proveniente-s dos demonstrativos do resultado econômico (ou, no caso presente, do resultado anual previsto de acôrdo com o plano geral de atividade, PGA). ${ }^{\circ}$

\begin{tabular}{lc|c}
\hline & Cr\$1.000,00 & $\%$ \\
\cline { 2 - 3 } Venda (anual) & 42.623 & 100,0 \\
DPV & 8.525 & 20,0 \\
CIF\{ Matéria-prima & 12.658 & 29,7 \\
CmL & 8.440 & 19,8 \\
\cline { 2 - 3 } & 13.000 & 30,5 \\
\hline
\end{tabular}

$\mathrm{CmL} / \mathrm{CITFL}=\frac{13.000}{8.440}=1,54 \frac{\mathrm{Cr} \$ \text { de CmL }}{\mathrm{Cr} \$ \text { de CITfL }}$

Dados do produto:

\begin{tabular}{cc|c}
\hline & Cr\$ & $\%$ \\
\cline { 2 - 3 } $\begin{array}{c}\text { Preço de venda } \\
\text { DPV }\end{array}$ & $\frac{x}{100}$ \\
CIF Matérla-prima & $\frac{36,00}{20}$ & $=$ \\
Total & 17,00 & $=$ \\
& 53,00 & - \\
\hline
\end{tabular}

0 preço de venda do produto deverá ser tal que traga, para a emprêsa, a mesma contribuição marginal por cruzeiro de custo de transformação, que os demais produtos da linha.

Portanto:

$$
\mathrm{Cm}=1,54 \times 17,00=\mathrm{Cr} 26,20
$$

E teremos:

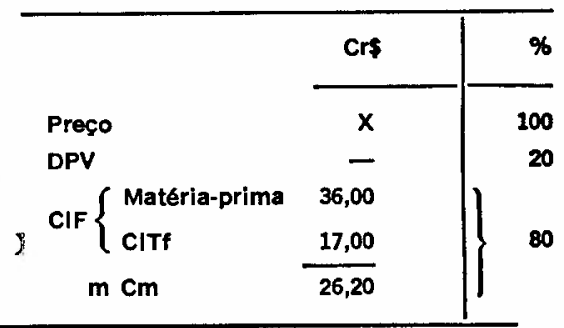

0 custo de fabricação mais a contribuição marginal correspondem, juntos, a $80 \%$ do preço, e perfazem um montante de $\operatorname{Cr} \$ 79,20$. Portanto:

$$
\begin{gathered}
\text { Preço-base } x=\frac{36,0+17,0+26,20}{0,80}= \\
=\frac{79,20}{0,80}=\operatorname{cr} \$ 99,00
\end{gathered}
$$

0 que significa que, vendendo o produto por $\mathrm{Cr} \$ 99,00$, teremos - mesmo aproveitamento da capacidade produtiva para formar a contribuição marginal global da emprêsa.

Se o mercado não suportar êsse preço, é evidente que o produto vai acarretar abaixamento nos lucros, por utilizar uma capacidade produtiva para obter uma contribuição inferior àquela que conseguiria se produzisse outros produtos da linha.

Obs.: 0 modêlo também é aplicável para os casos em que a capacidade produtiva e a parcela dessa capacidade, que o produto absorve, são medidas através de outras grandezas como tonelada, metro linear ou $\mathrm{m}^{2}$, hora $\times$ máquina de um determinado centro produtivo, e outras

\subsection{Terceiro caso}

Suponhamos agora uma situação em que o capital de giro a ser empregado para a produção e comercialização do nôvo produto deva continuar trazendo, no mínimo, a mesma contribuição marginal para a emprêsa.

Vamos supor que podemos associar à linha de produtos alguns dos elementos

\footnotetext{
- Conforme comentado no Item 2.4, a capacidade produtiva útll pode ser medlda pelo montante de gastos de transformação que a empressa teria quando trabalhando a plena carga.

- CITf - Custo incremental de transformaçăo.

- Ver o 2.0 artigo da série mencionada, RAE, 10 (1): mar. 1970.
} 
que compõem o capital de giro, de modo a conhecer a parte dêsse capital que é necessária para a comercialização e produção dos respectivos produtos. E vamos impor que a relação entre a $\mathrm{Cm}$ e o capital de giro necessário para o nôvo produto seja a mesma daquela da linha.

Teremos, então, os seguintes elementos conhecidos:

DADOS DA LINHA (anual)

\begin{tabular}{|c|c|c|}
\hline & Cr\$ $1.000,00$ & $\%$ \\
\hline Venda & 42.623 & 100,00 \\
\hline - DPV & 8.525 & 20,00 \\
\hline $\int \mathrm{MPrL}$ & 12.658 & 29,7 \\
\hline CITfL & 8.440 & 19,8 \\
\hline$=\mathrm{CmL}$ & 13.000 & 30,5 \\
\hline
\end{tabular}

DADOS DO PRODUTO "A"

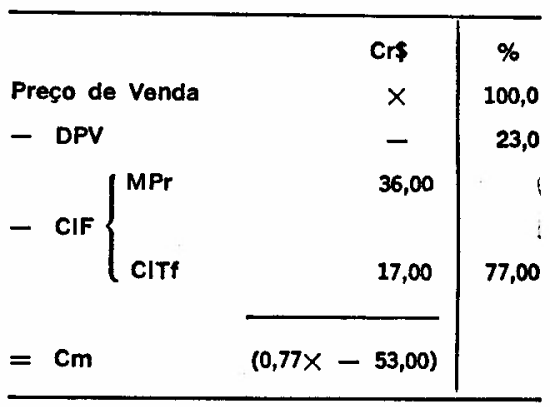

Parcelas do Capital de Giro

MEDIA DA LINHA

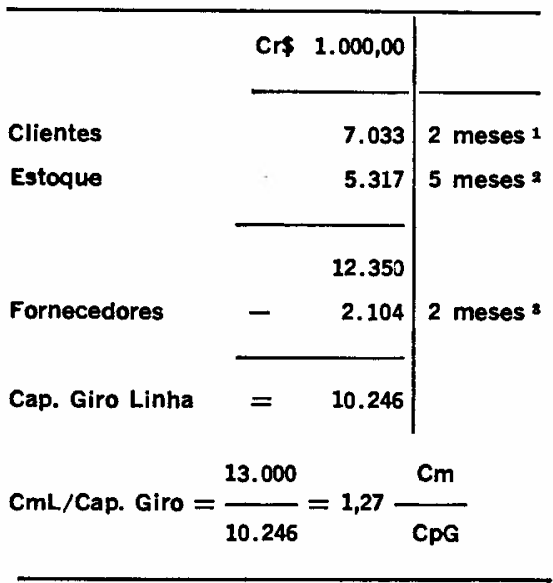

PROJETADO PARA O PRODUTO "A"

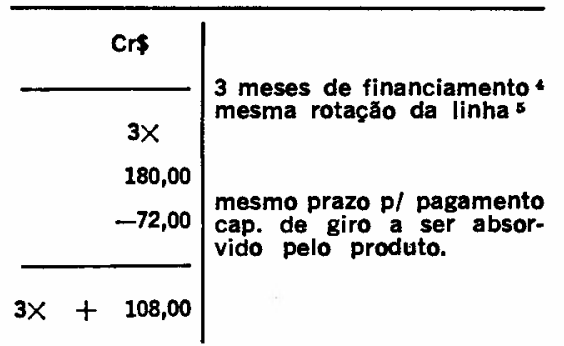

Cm mensal/Cap. Giro $=\frac{0,77 x-53,00^{\circ}}{3 x+108,00}$

1 Corresponde a um prazo médio de financiamento aproximadamente de 60 dias.

20 estoque (considerado para efeito de simplicidade do exemplo, apenas o valor da matériaprima) dá para atender cinco meses de produção.

3 Prazo médio para pagamento de fornecedores.

40 produto será vendido com um prazo médio de financiamento de três meses. Portanto, a venda de 1 unidade por mês acarretará um volume médio de financiamento aps clientes de 3X.

5 Projeção feita com base sòmente no valor da matéria-prima.

- Essa é a $\mathrm{Cm}$ mensal a ser conseguida por unidade de capital de giro absorvido. Para comparar com o dado da linha é preciso que haja transformação em indice anual.
Para que o capital de giro aplicado na produção e comercialização do produto $A$ traga, no mínimo, a mesma contribuição marginal que se obteria se aplicado nos demais produtos da linha, devemos ter:

Cm L/Cap.G.Linha $=\mathrm{Cm} /$ Cap.G.Produto

E, portanto, fazendo a homogeneização dos índices para período idêntico, teremos:

$$
\frac{1,27}{12}=\frac{0,77 x-53,00}{3 x+108,00}
$$

Resolvendo a equação, chegamos ao preço-base:

$$
X=\operatorname{Cr} \$ 142,00
$$

Se modificarmos o prazo de financiamento ao cliente de três para dois meses, teremos:

$$
\frac{1,27}{12}=\frac{0,77 x-53,00}{2 x+108,00}
$$

E o preço-base será:

$$
X=\operatorname{Cr} \$ 115,00
$$

\subsection{Quarto caso: fixação do preço de serviço}

Suponhamos agora que um cliente faça uma encomenda do produto A para a qual êle fornece a matéria-prima.

O serviço assim prestado deverá trazer, de um modo geral, uma compensação satisfatória para o esfôrço de transformação, de maneira que seja, na pior das hipóteses, equivalente àquela que se teria se estivesse sendo usada matéria-prima própria. Isso equivale a dizer que a contribuição marginal em relação à capacidade de produção absorvida deve ser, no mínimo, igual à da linha

\begin{tabular}{|c|c|c|}
\hline Dados da linha: & Cr\$ $1.000,00$ & $\%$ \\
\hline $\begin{array}{l}\text { Venda } \\
\text { DPV }\end{array}$ & $\begin{array}{r}42.623 \\
8.525\end{array}$ & $\begin{array}{r}100,0 \\
20,0\end{array}$ \\
\hline CIF $\left\{\begin{array}{l}\text { Mat. pr. } L \\
\text { CITfL }\end{array}\right.$ & $\begin{array}{r}12.658 \\
8.440\end{array}$ & $\begin{array}{l}29,7 \\
19,8\end{array}$ \\
\hline $\mathrm{CmL}$ & 13.000 & 30,5 \\
\hline
\end{tabular}
correspondente.

Teríamos, então (ver segundo caso): 
A contribuição em relação à capacidade de produção absorvida é:

$$
\mathrm{CmL} / \mathrm{CITfL}=\mathrm{Cr} \$ 1,54 \frac{\mathrm{Cr} \$ \text { de } \mathrm{Cm}}{\mathrm{Cr} \$ \text { de CITf }}
$$

Obs.: Poderiam ser usadas outras unidades de medida para a capacidade produtiva (tonelada, metro linear, hora $\times$ máquina, etc.).

Dados do produto:

\begin{tabular}{lc|r}
\hline & Cr\$ & $\%$ \\
\cline { 2 - 3 } Preço de venda & $\frac{X}{-0}$ & 100 \\
DPV & $\frac{20}{-}$ \\
CIF $\left\{\begin{array}{l}\text { Mat. pr. } \\
\text { CITf }\end{array}\right.$ & $\overrightarrow{17,00}$ & - \\
Cm & - & - \\
\hline
\end{tabular}

Impondo a condição da mesma contribuição por capacidade absorvida, temos:

$\mathrm{Cm}=\mathrm{Cr} \$ 1,54 \times \mathrm{Cr} \$ 17,00=\mathrm{Cr} \$ 26,20$

e portanto:

\begin{tabular}{|c|c|c|}
\hline & $\mathrm{Cr} \$$ & $\%$ \\
\hline $\begin{array}{l}\text { Preço de venda } \\
\text { DPV }\end{array}$ & $\underline{x}$ & \multirow{3}{*}{$\begin{array}{r}100 \\
20 \\
80 \% \text { (por } \\
\text { diferença) }\end{array}$} \\
\hline CIF $\left\{\begin{array}{l}\text { Mat. pr. } \\
\text { CITf }\end{array}\right.$ & $\overline{17,00}$ & \\
\hline $\mathrm{Cm}$ & 26,20 & \\
\hline
\end{tabular}

Decorre daí:

Preço-base: $x=\frac{\operatorname{cr} \$ 17,00+\operatorname{cr} \$ 26,20}{0,80}=$

Cr $\$ 54,00$

Com êsse preço, o esfôrço de produção empregado na transformação da matéria-prima de terceiros trará a mesma compensação (contribuição), se aplicado para transformar matéria-prima própria.

\subsection{Fórmula sugerida para 0 cálculo do preço-base}

Comparando os preços encontrados dos casos segundo e quarto apresentados, verificamos, como era de se esperar, que a diferença está apenas no valor da matéria-prima (acrescida das despesas proporcionais de venda correspondente). Portanto, em ambos os casos estamos conseguindo a mesma remuneração pelo nosso trabalho, enquanto fornecemos, no segundo caso, a matéria-prima a preço de custo.
Esse fato nos sugere que, para efeito de cálculo, se considere o preço de venda decomposto em duas parcelas:

a) uma, apresentando a remuneração do trabalho de transformação;

b) outra, relativa à comercialização da matéria-prima, sôbre a qual podemos introduzir também um fator de lucro, fornecendo-a a um preço superior ao de custo.

Assim, teremos o preço de venda base, $X$, como a soma de dois outros $\mathbf{X t}$, referente ao esfôrço de transformação, e Xm, correspondendo ao material fornecido (matéria-prima).

Então:

$x=x_{\text {onde }} t+X_{m},\left\{\begin{array}{l}x_{t}=\frac{\operatorname{CITf}\left(1+\frac{C m L}{C I T f L}\right)}{1-(\% D P V / 100)} \\ x_{m}=\frac{k \cdot M P r}{1-(\% D P V / 100)}\end{array}\right.$

Em que:

( $\mathrm{CmL} / \mathrm{CITfL})$ é o índice desejado de contribuição em relação à capacidade de trabalho absorvida;

k é o fator de lucro na comercialização da matéria-prima;

\% DPV é a porcentagem das despesas proporcionais de venda.

O fator $\mathbf{k}$ mencionado deverá ser calculado de modo a cobrir os gastos e riscos adicionais que se têm quando a matéria-prima é própria. Inclusive pode-se levar em conta o custo do capital adicional necessário à comercialização e estocagem do material.
A fórmula de aplicação relativamente simples pode ser empregada, de um modo geral, em grande número de casos. Sua utilização deve ser acompanhada dos mesmos cuidados comentados no início dêste artigo, ou seja:

a) ter sempre em mente que o preço calculado deve ser submetido a uma apreciação à luz das condições do mercado;

b) os índices adotados devem ser revistos periòdicamente e estabelecidos, tendo em consideração a situação global da emprêsa, mostrada através dos demonstrativos econômico-financeiros;

c) todo o processo deve ter a orientação geral de um elemento competente, conhecedor da problemática econômico-financeira da emprêsa, e com condições para corrigir eventuais distorções que podem ocorrer em casos especiais.

\subsection{Caso de Concorrências}

Emprêsas que trabalham para órgãos governamentais são frequientemente chamadas para participar de concorrências públicas para o fornecimento de seus produtos. A fixação de preços, nesses casos, reveste-se de grande importância, pois êsses preços devem ser inferiores aos dos concorrentes e ao mesmo tempo deve garantir o interêsse da emprêsa. Geralmente, em se tratando de grandes concorrências, o volume em questão, uma vez aceito o pedido, pode alterar sensivelmente as condições da emprêsa em têrmos de absorção da capacidade de produção (pessoal e equipamento) e aproveitamento do capital de giro, e essa influência deve ser considerada ao se fixar o preço para entrar na concorrência. Os exemplos apresentados podem servir de orientação para a solução do presente caso. 


\section{CONCLUSÃO}

Com êsses exemplos, queremos mostrar que o preço de venda dos produtos está condicionado a diversos aspectos econômico-financeiros da emprêsa, e que essas injunções devem ser verificadas $e$ controladas por ocasião da respectiva determinação.

A utilização de um custo global do produto característico dos sistemas de custo por absorção (como o RKW, por exemplo) - como ponto de partida para o cálculo dos preços, não permite examinar com facilidade as influências acima mencionadas. Já a contabilidade decisorial, baseando-se, para efeito de cálculo de preço, no conceito da contribuição marginal, oferece os meios para uma verificação rápida $e$ simples das conseqüências que um preço fixado trará para os diversos aspectos econômico-financeiros envolvidos.

Com êsses casos simples que apresentamos, acreditamos ter dado uma idéia sôbre alguns caminhos que poderão ser seguidos para os estudos de preços, empregando os conceitos da contabilidade decisorial.

Recomendados, para finalizar, que a adoção de um procedimento de cálculo seja precedida de um estudo cuidadoso das caracteristicas da emprêsa e do mercado, e que seja feita, periòdicamente, uma revisão completa do processo e dos índices empregados.

\section{REFERENCIAS \\ BIBLIOGRAFICAS:}

\section{Beyer, Robert. Profitability accounting for planning and control. New York, The Ronald Press Company, 1963.}

Dean, Joel. Economia de emprêsas. Rio de Janeiro, Fundo de Cultura.

Dias, Ivan Pinto. Algumas observações sôbre a margem de contribuição. Revista de Administração de Emprêsas, Rio de Janeiro, Fundação Getúlio Vargas, 7(24): set. 1967.

Schoeps, Wolfgang. 0 método de custeio direto. Revista de Administração de Emprêsas, Rio de Janeiro, Fundação Getúlio Vargas, 1(2): set./dez. 1961.

Werolin, A. E. A elaboração de um orçamento variável. Revista de Administração de Emprêsas, Rio de Janeiro, Fundação Getúlio Vargas, 5(16): set. 1965.

Paranhos, J.L.B. A contabilidade decisorial. Um sistema integrado de informações para diretores e gerentes. Revista de

Administração de Emprêsas, Rio de Janeiro, Fundação Getúlio, Vargas, 9(1): jan./mar. 1969.

Paranhos, J.L.B. "A contabilidade decisorial em seu segundo estágio: o planejamento geral das atividades: $1 .^{a}$ parte. R.A.E., 10(1): jan./mar. 1970. 2. ${ }^{\mathrm{a}}$ parte. R.A.E., 10(2):abr./jun. 1970.

\section{RELAÇão DE ANUNCIANTES}

Caraíba Metais S.A. -

Ind. e Com.

Casas da Banha

Com. e Ind. S. A.

Coca-Cola

Ind. e Com. Ltda.

Construtora Barbosa

Mello S. A.

S. A. Fábrica de

Tecidos Santa

He'ena

Philips Electrológica,

Máquinas e Serviços

Os contactos para inserção de anúncios na Revista de Administração de Emprésas ou Conjuntura Econômica deverão ser feitos com o nosso departamento de vendas ou com a REPRENAES, agência autorizada em todo o Brasil a representar a Editôra da Fundação Getúlio Vargas em qualquer aspecto relativo à publicidade.

O nosso departamento funciona na Praia de Botafogo, 188 - CP $21.120-$ zC - 05 - Telefone: 246-5107

(Procurar o Sr. Albertino Ferro da Silva).

Quanto à REPRENAES, eis os seus endereços:

Guanabara - Travessa do Paço, 23 11. ${ }^{\circ}$ andar - Telefone: 231-4061

São Paulo - Rua 7 de Abril, 261 5..$^{\circ}$ andar - Telefones: $239-0448$ e 35-4948.

Belo Horizonte - Av. Amazonas, 314 — s/ 937 - Telefone: 22-1471

Salvador - Travessa Bonifácio Costa, 1 - s/ 201 - Telefone: 3-5284.

Recife - Rua Aurora, 1071

- s/ 808 - Telefone: 4-2239.

Fortaleza - Rua Liberato Barroso, 397 - s/ 511 - Telefone: 26-2974.

Pôrto Alegre - Travessa Francisco Leonardo Truda, 40, 9. ${ }^{\circ}$ andar Telefone: 9-1778.

Niterói - Avenida Amaral Peixoto, 55, s/ 906 - Telefone 5224.

Brasília - Ed. Casa de São Paulo, 7." andar - Setor Bancário Sul Telefone: $43-2500$. 